\title{
Comparison of Isolation Ratios of the Scapular Retraction Muscles between Protracted Scapular and Asymptomatic Groups
}

\author{
WON-GYU Yoo ${ }^{1)}$ \\ 1) Department of Physical Therapy, College of Biomedical Science and Engineering, Inje University \\ and Elderly Life Redesign Institute: 607 Obang-dong, Gimhae, Gyeongsangnam-do 621-749, \\ Republic of Korea. TEL: +82 55-320-3994, FAX: +82 55-329-1678
}

\begin{abstract}
Purpose] The purpose of this study was to compare the isolation ratios of scapular retraction muscles between protracted scapular and asymptomatic groups. [Subjects] Seven males with protracted scapular and seven asymptomatic males aged 20-30 years were recruited. [Methods] We measeured the rhomboid, middle trapezius (MT), and lower trapezius (LT) muscles activities, and calculated the isolation ratio. [Results] The rhomboid and MT isolation ratio of the protracted scapular group was not significantly different from that of the asymptomatic group. The LT isolation ratio of the protracted scapular group was significantly lower than that of the asymptomatic group. [Conclusion] We suggest that a proper retraction exercise, for patients with protracted scapular posture is one that includes exercises for selectively strengthening the lower trapezius muscle.

Key words: Lower trapezius, Protracted scapular, Scapular retraction exercise
\end{abstract}

(This article was submitted Feb. 20, 2013, and was accepted Mar. 20, 2013)

\section{INTRODUCTION}

In rehabilitation, the scapular orientation is one of the major factors utilized in normalizing scapulohumoral rhythm ${ }^{1)}$. The shoulder muscles contribute to scapular upward rotation, external roation and the posterior tilt of the acromioclavicular joint, and substantial protraction of the clavicle at the sternoclavicular joint ${ }^{2}$. Scapualr protraction is not only a movement of anterior translation of the acromioclavicular joint ${ }^{3)}$. Accordingly, some clinicians suggest the necessity of a proper retraction exercise for patients with a protracted scapular posture ${ }^{4)}$. Retractors of the scapulothoracic joint consist of the middle trapezius, rhomboids and lower trapezius ${ }^{5}$. These muscles are particularly active during pulling movements of the arms. The middle trapezius functions as the primary muscle, and the rhomboids and lower trapezius have secondary roles ${ }^{5}$. The isolated contraction ratio is calculated as the ratio of co-activatied muscles ${ }^{6)}$. In the present study, the isolated contraction ratio was calculated using the following formula: Isolation ratio $=[$ Muscle A or B or C / (Muscle A + Muscle B + Muscle C $)]$ $\times 100 \%$. The isolated contraction ratio indicates the proportional contribution of a muscle to a motion. This study compared the isolation ratios of the scapular retraction muscles between protracted scapular and asymptomatic groups.

\section{SUBJECTS AND METHODS}

We performed an evaluation for protracted scapular when we recruited the subjects. A palpation meter (PALM; Per-

E-mail: won7y@inje.ac.kr formance Attainment Associates, St. Paul, MN, USA) was used to measure the distance between two bony landmarks of the body. We measured the horizontal distance between the scapula medial border and the spine in the scapular resting position ${ }^{7}$. This procedure was repeated 3 times, and the average of the measurements was used. Normally, the scapular resting position is the position on the posterior thorax approximately 2 inches from midline ${ }^{2)}$. In this study, we determined the protracted shoulders as a distance of more than $9 \mathrm{~cm}$ from the spine and a distance of between $5-7 \mathrm{~cm}$ was considered an asymptomatic sign. Seven asymptomatic males aged 20-30 years with a mean height and weight of $173.2 \pm 3.3 \mathrm{~cm}$ and $67.1 \pm 4.0 \mathrm{~kg}$, respectively, participated in this study. Seven males with protracted scapular aged 20-30 years with a mean height and weight of $174.1 \pm$ $2.6 \mathrm{~cm}$ and $65.2 \pm 5.3 \mathrm{~kg}$, respectively, participated in this study. None of the subjects had a history of musculoskeletal disorders or pain associated with the upper extremity in the past 6 months. EMG data of the rhomboid, middle trapezius (MT), and lower trapezius (LT) muscles activities were collected using a Biopac MP100WSW (Biopac System, Santa Barbara, CA, USA) data acquisition system. All EMG signals were sampled at $1,000 \mathrm{~Hz}$, and the root mean square values were calculated. The amplitude was normalized to the maximum voluntary isometric contraction. The isolated contraction ratio was calculated using the normalized data of the three scapular retractor muscles activities. Each scapular retractor muscle's isolation ratio was calculated using the following formula ${ }^{6}$ ): isolation ratio $(\%)=$ rhomboid or MT or LT / (rhomboid + MT + LT) $\times 100 \%$. All subjects performed a scapular retraction exercise using tubing band with their elbows at their sides and bent to 90 degrees. They 
pulled the band back to move their shoulder blades toward each other, then returned to the starting position. One trial was performed for each test. The Statistical Package for Social Sciences (SPSS, Chicago, IL, USA) was used for the statistical analysis. The independent t-test was performed to analyze the significance of differences between the groups. The level for statistical significance, $\alpha$, was chosen as 0.05 .

\section{RESULTS}

The rhomboid isolation ratio of the protracted scapular group $(40.6 \pm 6.2 \%)$ was not significantly different from that of the asymptomatic group $(37.0 \pm 5.7 \%)(\mathrm{p}>0.05)$. The MT isolation ratio of protracted scapular group $(36.8 \pm 8.3 \%)$ was not significantly different from that of the asymptomatic group $(34.2 \pm 6.4 \%)(\mathrm{p}>0.05)$. The LT isolation ratio of protracted scapular group $(22.4 \pm 5.7 \%)$ was significantly lower than that of the asymptomatic group $(28.6 \pm 5.1 \%)$ $(\mathrm{p}<0.05)$

\section{DISCUSSION}

The middle trapezius functions as the primary muscle, and the rhomboids and lower trapezius function as secondary muscles during scapular retraction movements ${ }^{5}$. MT has a proper line force to retract the scapular. The scapular elevation is controlled by the LT and scapular depression is controlled by the rhomboid ${ }^{5}$. The isolated contraction ratio indicates the relative proportion of a muscle's role during a motion. Our results show that the rhomboid and MT isolation ratios of the protracted scapular group were not significantly different from those of the asymptomatic group. The LT isolation ratio of the protracted scapular group was significantly lower than that of the asymptomatic group. Weakness of the LT or rhomboids significantly reduces the retraction of the scapular ${ }^{5)}$. Weakness of the lower trapezius causes poor scapular orientation and instability, and is attributed to pathologic kinematics such as impingement ${ }^{8)}$. A recent study reported that postural correction of the scapula was closely associated with activation of the lower trapezius in neck pain patients ${ }^{9}$. Several researchers have proposed activating the lower trapezius, to restore normal scapulothoracic and glenohumeral joints movements ${ }^{6,10)}$. Postural correlates have been described without quantitative verification. For example, a forward head tilt or forward shoulders are related to an extended upper cervical spine, or to protracted scapular and a kyphotic thoracic spine ${ }^{11)}$. Clinicians commonly apply a simple scapular retraction exercise, such as pulling a band back to move the shoulder blades together, with the elbows at the sides and bent at 90 degrees, for scapular protraction posture. However, we suggest that a proper retraction exercise for patients with protracted scapular posture requires an exercise selectively strengthening the lower trapezius muscle.

\section{ACKNOWLEDGEMENTS}

This research was supported by Basic Science Research Program through the National Research Foundation of Korea (NRF) funded by the Ministry of Education, Science and Technology (No. 2012R1A1B4001058).

\section{REFERENCES}

1) Phadke V, Camargo P, Ludewig P: Scapular and rotator cuff muscle activity during arm elevation: a review of normal function and alterations with shoulder impingement. Rev Bras Fisioter, 2009, 13: 1-9. [Medline] [CrossRef]

2) Ludewig PM, Cook T: Alternations in shoulder kinematics and associated muscle activity in people with symptoms of shoulder impingement. Phys Ther, 2000, 80: 276-291. [Medline]

3) Park SY, Yoo WG: Differential activation of parts of the serratus anterior muscle during push-up variations on stable and unstable bases of support. J Electromyogr Kinesiol, 2011, 21: 861-867. [Medline] [CrossRef]

4) De Mey K, Danneels L, Cagnie B, et al.: Kinetic chain influences on upper and lower trapezius muscle activation during eight variations of a scapular retraction exercise in overhead athletes. J Sci Med Sport, 2013, 16: 65-70. [Medline] [CrossRef]

5) Neumann DA: Kinesiology of the musculoskeletal system: foundations for physical rehabilitation. St Louis: Mosby, 2002.

6) Arlotta M, Lovasco G, McLean L: Selective recruitment of the lower fibers of the trapezius muscle. J Electromyogr Kinesiol, 2011, 21: 403-410. [Medline] [CrossRef]

7) da Costa BR, Armijo-Olivo S, Gadotti I, et al.: Reliability of scapular positioning measurement procedure using the palpation meter (PALM). Physiotherapy, 2010, 96: 59-67. [Medline] [CrossRef]

8) Mottram SL: Dynamic stability of the scapula. Man Ther, 1997, 2: 123 131. [Medline] [CrossRef]

9) Wegner S, Jull G, O'Leary S, et al.: The effect of a scapular postural correction strategy on trapezius activity in patients with neck pain. Man Ther, 2010, 15: 562-566. [Medline] [CrossRef]

10) Ludewig PM, Hoff MS, Osowski EE, et al.: Relative balance of serratus anterior and upper trapezius muscle activity during push-up exercises. Am J Sports Med, 2004, 32: 484-493. [Medline] [CrossRef]

11) Hanten WP, Lucio RM, Russell JL, et al.: Assessment of total head excursion and resting head posture. Arch Phys Med Rehabil, 1991, 72: 877-880. [Medline] [CrossRef] 